\title{
School accidents to children: time to act
}

\author{
Asit Maitra
}

\begin{abstract}
Objective-To describe the profile of injuries sustained by children in school accidents and suggest preventive measures. Design-A five month prospective study of children attending an urban accident and emergency (A\&E) department. Subjects-500 children who sustained injuries in school due to a variety of activities.

Results-10 and 12 year old pupils suffered most injuries in school grounds/ playgrounds, on concrete, or on grass/soil surfaces due to random activities resulting in striking or being struck by objects/ persons, tripping or slipping, and sports (mainly football); $\mathbf{6 5 . 6 \%}$ of these activities were not supervised and $67.4 \%$ occurred "out of lessons"; $22 \%$ sustained fractures or dislocations, $28.2 \%$ needed follow up treatment, and $1.4 \%$ were admitted. Conclusions-Injuries to children in school are a cause for concern. Effective preventive measures should concentrate on (a) specific target areas using schemes based on individual schools, and (b) establishing a credible system of monitoring of their effectiveness.

(F Accid Emerg Med 1997;14:240-242)
\end{abstract}

Keywords: school; injury; causes; prevention

The Leisure Accident Surveillance System (LASS) reported an increase in injuries to children (aged 5-16 years) in school between 1988 and $1991^{12}: 8440$ children sustained fractures/ dislocations in 1991 compared to 6596 in 1989 in England and Wales. The data were collected from the same 18 hospitals during the two periods of study. A Canadian study found the incidence of school related injuries to be $2.82 /$ 100 students per year, although it varied from 1.7 to $5.4 .^{3}$ The rate of accidents due to all leisure activities (including school) was estimated by LASS in $1994^{3}$ to be $13.5 / 100$ per year nationally among the 3-16 age group.

School accidents causing injuries have not been as widely investigated as other causes of injury to children. ${ }^{4}$ This reflects the general belief that children are relatively protected in school because of the safe environment and supervision. A previous study ${ }^{5}$ has shown that fractures/dislocations following school accidents are proportionally as frequent as those in public places. That study compared specific injuries sustained in schools with those occurring in public places, or places outside school, home, or work without involving sports or road traffic accidents. The investigators suggested that accident prevention measures should start at individual schools, based on local accident details and initiatives.

The aim of the present prospective study was to describe a profile of injuries sustained in schools requiring attendance at a large urban hospital accident and emergency (A\&E) department, identify individual schools, and initiate locally based accident prevention measures.

\section{Methods}

A target was set to analyse prospectively 500 school injuries which required attendance at the A\&E department of the Royal Victoria Infirmary, Newcastle, and this target was reached within five months (mid-February to mid-July 1994, excluding school holidays during Easter). During this period there was no unexpected average increase or decrease in the numbers of attendances of injured schoolchildren due to seasonal variation. These 500 injured children constituted $6.6 \%$ of the total number of children from all accidents, compared to $35 \%$ for home accidents and $6 \%$ for sports accidents. Using a proforma, the initial information was collected by the triage nurse from the children, parents, and accompanying persons as appropriate. Subsequent details were filled in by the medical staff. The proforma recorded the name and the type of the school (that is, state or private, primary, middle, or secondary), area of the school where the accident occurred, type of surface involved (if applicable), whether the activity was organised/supervised or not, what the specific activity was, and when during school time the accident took place. Demographic and clinical details were also recorded. The information was coded and analysed using Minitab statistical package.

\section{Results}

AGE

In primary schools, there was a progressive increase in accidents with age. In middle and secondary schools, accidents were more frequent among the 12-14 year olds (fig 1).

SEX

There were more boys (59\%) than girls $(41 \%)$ who suffered injuries. Among the 10-11 year olds, girls $(12.2 \%)$ outnumbered boys $(10 \%)$.

TYPE OF SCHOOL

Injured children came from 144 different schools (nine private and 135 state) in and around Newcastle. From 104 of the schools the number of injured children varied between one and three per school; 27 schools each sent 
Table 1 Details of 500 school accidents

\begin{tabular}{lc}
\hline Subject & Number (\%) \\
\hline Site of accident & \\
School grounds (including playground) & $207(41.4)$ \\
School building (not gymnasium or sports & \\
hall) & $109(21.8)$ \\
Outdoor sports field & $101(20.2)$ \\
Gymnasium and sports hall & $83(16.6)$ \\
Specific activities causing injuries & \\
Sports & $140(28.0)$ \\
Non-sport contact (striking/struck by) & $140(28.0)$ \\
Unrelated falls & $89(17.8)$ \\
Tripped/slipped & $59(11.8)$ \\
Physical education & $27(5.4)$ \\
Gymnasium & $26(5.2)$ \\
Miscellaneous & $19(3.8)$ \\
School time of accidents & \\
During lessons & $163(32.6)$ \\
"Outside of lessons" & \\
Total & $337(67.4)$ \\
Before lessons & $33(6.6)$ \\
Between lessons & $47(9.4)$ \\
Break time & $112(22.8)$ \\
Lunch time & $121(24.2)$ \\
After school & $24(4.8)$ \\
Anatomical sites of injuries & \\
Head/neck/face & $127(25.4)$ \\
Fingers and thumbs & $79(15.8)$ \\
Wrist & $71(14.2)$ \\
Ankle/foot/toes & $71(14.2)$ \\
Lower limbs & $43(8.6)$ \\
Hand & $41(8.2)$ \\
Trunk pelvis & $14(2.8)$ \\
\hline
\end{tabular}

between four and nine injured children, and nine schools sent between 10 and 28 .

Primary school accounted for $42.4 \%$ of the injuries, and middle and secondary schools for $57.6 \% ; 87.2 \%$ of injured children were from state schools. There was no significant difference in the likelihood of receiving injuries in private or state schools.

DETAILS OF SCHOOL ACCIDENTS

Table 1 shows some of the details of the 500 school accidents. The majority of accidents occurred in school grounds. Sports and non-sports random activities caused most of these accidents. Falls were a common cause of injury. Some falls, however, were random and unrelated to other activities. Twice as many accidents occurred "outside of lessons" as during lessons, the latter including physical education (PE), gymnastics and sports. Some sports caused specific injuries-for example injury to the wrist was common in football and to the hands and digits in netball and volleyball. Football, in particular, caused a large number of fractures and dislocations (table 2).

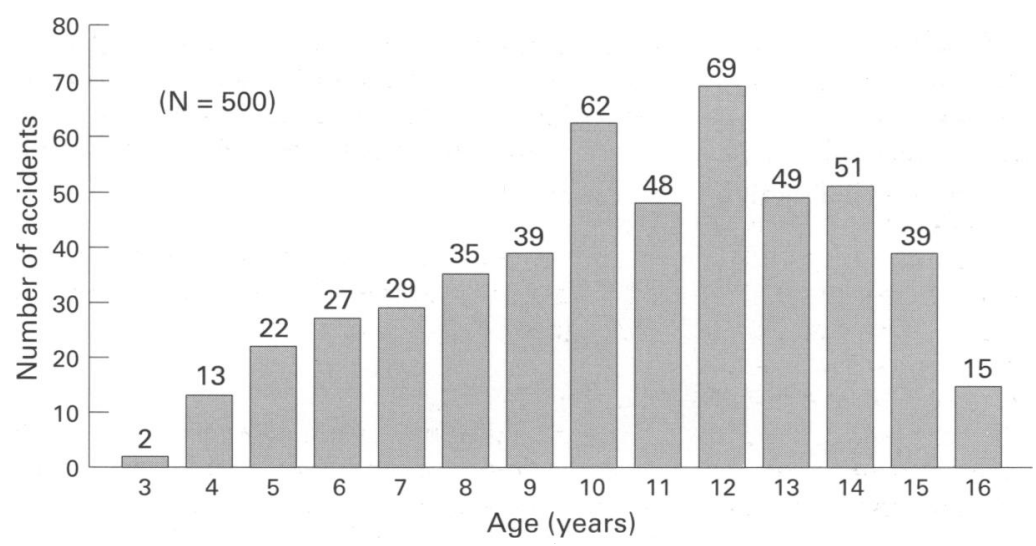

Figure 1 Age distribution in relation to numbers of accidents.
Table 2 Different sports causing injuries including fractures/dislocations $(n=140)$

\begin{tabular}{lcc}
\hline Sport & Total (\%) & $\begin{array}{l}\text { Fractures/ } \\
\text { dislocations (\%) }\end{array}$ \\
\hline Football & $72(14.4)$ & $23(32)$ \\
Netball & $13(2.6)$ & 0 \\
Basketball & $12(2.4)$ & $2(2.8)$ \\
Athletics & $11(2.2)$ & $3(4.2)$ \\
Cricket & $10(2.0)$ & $2(2.8)$ \\
Rugby & $8(1.6)$ & $1(1.4)$ \\
Rounders & $8(1.6)$ & $1(1.4)$ \\
Volley ball & $4(0.8)$ & $1(1.4)$ \\
Hockey & $2(0.4)$ & $1(1.4)$ \\
\hline
\end{tabular}

SUPERVISION OF ACTIVITIES AND SURFACE

INVOLVED

Most (65.6\%) of the activities were not organised or supervised. Concrete and grass/soil surfaces were more frequently associated with the accidents than other surfaces (fig 2).

SEVERITY OF INJURIES

Most injuries (57.8\%) were to soft tissues (bruises, sprains, etc); $22 \%$ sustained fractures or dislocations, $18 \%$ lacerations or grazes, and the remainder miscellaneous injuries; $44.5 \%$ of fracture/dislocations occurred in school grounds and $68.2 \%$ during unsupervised activities. The abbreviated injury scale score ranged from 1 to 3 . Multiple injuries were uncommon.

TREATMENT AND DISPOSAL

In $89.2 \%$ of the injuries, only simple bandaging and advice were needed; $10.4 \%$ required a plaster cast or splint, and there were two operations for fracture and nerve/tendon injury. Most of the children (70.4\%) were discharged but $28.2 \%$ needed further treatment as outpatients. Seven children were admitted, four because of fracture/dislocations.

\section{Discussion}

School accident prevention initiatives require up to date and locally based epidemiological studies which can form the basis of practical schemes for accident prevention. A study in Glasgow $^{6}$ kickstarted such a worthwhile scheme.

The general profile of school accidents has been documented by various studies, ${ }^{4-11}$ which have also identified the main target areas for accident prevention. These are (1) vulnerable age group and sex, (2) school environment, for example specific areas of school and nature of surface, and (3) the organisation and supervision of specific activities. The present study generally confirms these findings and gives a good profile of the local school accidents and injuries.

The accident rate in the different schools in this study varied from 1.1 to $4.9 / 100$ pupils per year, similar to other studies. ${ }^{47}$ The epidemiology of age and sex is also similar to those published. Boys aged 8-10 years in primary school and 12-14 years in middle and secondary schools, and girls in the 10-11 year group (playing netball and rounders), were most commonly injured and need targeting for preventive action. 


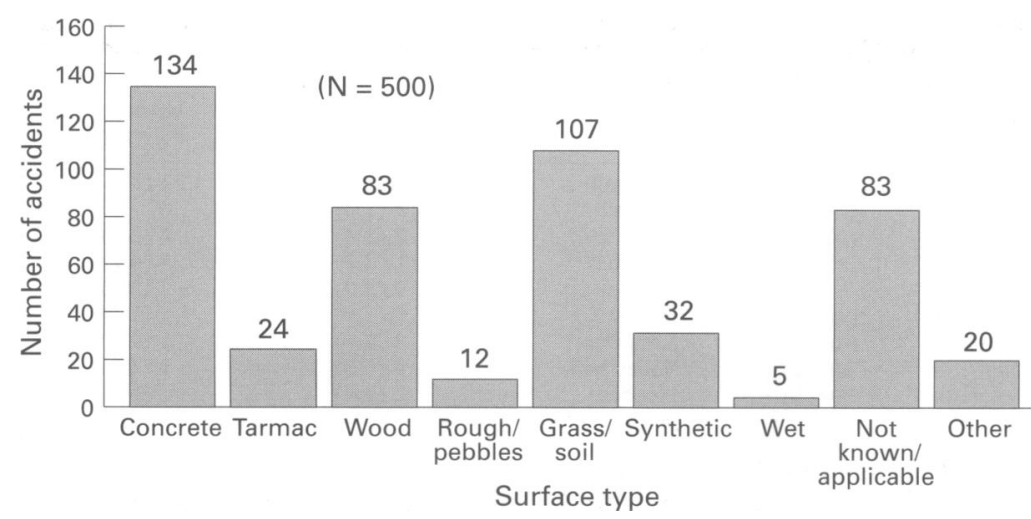

Figure 2 Details and frequency of types of surface involved in accidents.

School grounds, including playgrounds with concrete or grass/soil surface, have been highlighted $^{8-10}$ as the most frequent site of the accidents, as in the present study, because the children spend a substantial part of their school time there. These injuries are caused with or without the involvement of equipment, ${ }^{7}$ pointing to lack of safety in the environment.

Among the activities causing accidents, football-the most widely played sport-was a primary cause, as reported by others. ${ }^{910}$ Preventive measures would need to concentrate on more training and supervision. Injuries during PE and gymnastics are a cause for concern because these activities are supervised, so injuries should in theory be prevented or reduced.

A significant number of injuries (28\%) were caused by physical contact due to striking or being struck by objects/persons, usually when not under supervision. A Swedish study ${ }^{8}$ had reported a similar mechanism of injury in $36 \%$ of the pupils in a comprehensive school and suggested unsatisfactory interaction and schoolmate relationship as one of the factors in the injuries. LASS also highlighted "striking contact" as the second common cause of school playground accidents. ${ }^{3}$ "Unrelated falls"-another important cause of injury in this study-occurred, for example, when a child sitting unbalanced on a boundary wall or the edge of a bench fell because of loss of balance or through being pushed while sitting. In most of these accidents the children were not supervised. Preventive action lies in modifying the behaviour of children by education (school safety pack in course curriculum), supervision (enlisting the support of parents), and personal and group involvement (stakeholder in safety).

Although most school injuries are not serious, previous studies ${ }^{49}$ had highlighted the risks of fractures/dislocations in school accidents, especially during unsupervised activi- ties, implying undoubted scope for improvement. The hospital admission rate of $1.4 \%$ in this study is similar to those published elsewhere (0.91 to $1.7 / 100$ students per year). ${ }^{4}$ This is reassuring but no cause for complacency.

A small number of the schools accounted for many more injured children than the others; this could not be explained by varying distance of the schools from the hospital or by the schools' referral pattern or the severity of injuries. This raises the important question of targeting safety in individual schools.

In conclusion, this study has provided a local profile of accidental injuries to children in school which required attendance in an A\&E department and identified schools which merit closer scrutiny. As a result of this study on behalf of the child accident and injury prevention group of the Newcastle Healthy City Project, one targeted primary school has set up a steering group involving dinner ladies, teachers, and pupils to start "lunchtime clubs" (chess, sewing, etc) and to teach more varied organised games during regular PE sessions. School governors, parents, and teachers are also meeting to decide what structural changes are necessary to make the playground environment safer.

A further study would be needed to assess the effectiveness of these measures. Some of the preventive initiatives may require extra resources, which is a price worth paying for the safety of our children in schools.

I would like to acknowledge helpful suggestions from $\mathrm{Dr} H$ Jackson of the Child Accident Prevention Trust, and Mr M Choyce and to Miss C Richards for typing the manuscript.

1 Consumer Safety Unit. Home and leisure accident research 12 th annual report. (Home accident surveillance system.) London: Department of Trade and Industry, 1988:47-8.

2 Consumer Safety Unit. Home and leisure accident research, 15 th annual report. (Home accident surveillance system.) London: Department of Trade and Industry, 1991:48-51.

3 Consumer Safety Unit. Home and leisure accident research, 18 th annual report. (Home accident surveillance system.) London: Department of Trade and Industry, 1994:46.

4 Scheps SB, Dewey Evans G. Epidemiology of school injuries: a 2-year experience in a municipal health department. Pediatrics 1987;79:69-75.

5 Maitra AK, Sweeney G. Are schools safer for children than public places? J Accid Emerg Med 1996;13:196-7.

public places? J Accid Emerg Med 1996;13:196-7.
6 Roberts H. Safe schools are not accidents. Barnados, Essex: Roberts H. Safe schools are not accidents. Barnados, Essex: No 4, 1993 .

7 Illingworth C, Brennan P, Jay A, Al-Rawi F, Collick M. Two hundred injuries caused by playground equipment. BMJ 1975;4:332-4

8 Bremburg S, Gerber C. Injuries at school. Influence of schoolmate interaction. Acta Paediatr Scand 1988;77 432-8.

9 Jacobson B, Bek-Jensen H, Janssion B. One year's incidence of school accidents and their severity in a Swedish municipality. Scand J Primary Health Care 1986;4:213-7.

10 Schelp L, Ekman R, Fahl I. School accidents during a three school year period in a Swedish municipality. Public Health 1991;105:113-20.

11 Feldman W, Woodward CA, Hodgson C, Harsonyiz Z, Milner R, Feldman E. Prospective study of school injuries: incidence, types, related fractures and initial management. Can Med Assoc J 1983;129:1279-83. 